\title{
A pesquisa e a produção brasileira de medicamentos a partir de plantas medicinais: a necessária interação da indústria com a academia
}

\author{
SIMÕES, C. M. O.*; SCHENKEL, E. P. \\ Departamento de Ciências Farmacêuticas, Centro de Ciências da Saúde, \\ Universidade Federal de Santa Catarina, Florianópolis, SC.
}

\begin{abstract}
Investigações recentes da CPI dos medicamentos (11/1999-5/2000) mostraram o quanto é urgente que o Brasil desenvolva-se rapidamente na área da pesquisa e da tecnologia, pois temos um mercado relevante, recursos naturais abundantes e recursos humanos qualificados. No entanto, investimos pouco em P\&D e somos altamente dependentes nas etapas de maior valor agregado do setor farmacêutico (103a Reunião Ordinária do Plenário do CONSELHO NACIONAL DE SAÚDE, 2001).
\end{abstract}

Recentemente, tem-se observado um entusiasmo sem precedentes na imprensa brasileira quanto às potencialidades de exploração dos recursos naturais. Jornais de grande circulação chamam a atenção para o valor da biodiversidade (Brasil aposta na sua horta, Folha de São Paulo, 29/4/2001); revistas apresentam chamadas de capa como O negócio do verde (Exame, 2/5/2001) e O poder verde (Isto É, 6/6/2001), onde são apresentados valores astronômicos para o patrimônio natural, estimado em 2 trilhões de dólares, e um mercado para terapias à base de plantas medicinais que movimenta, hoje, em torno de US $\$ 500$ milhões, somente no Brasil. Cifra esta pequena, se comparada aos valores publicados para a Europa e EUA, no ano de 2000: US\$ 8,5 e 6,3 bilhões, respectivamente. Esses valores indicam um mercado com potencial de expansão.

No segmento acadêmico, a convicção da importância dos recursos naturais para o desenvolvimento vem de longa data. Afinal, as plantas fazem parte da vida do homem desde seus primórdios e sua importância nos diversos estágios de desenvolvimento da sociedade é inegável.

Com respeito às potencialidades de nossa flora, já nos anos 80 , apontávamos que o entusiasmo em relação ao uso de plantas medicinais e seus extratos na assistência à saúde pode ser entendido pela sua aceitabilidade, derivada da inserção cultural e pela atual disponibilidade desses recursos, ao contrário do que ocorre com outros medicamentos, que na sua maioria são dependentes de matériaprima e tecnologias externas (SCHENKEL et al., 1985; SIMÕES et al., 1986).

$\mathrm{Na}$ área farmacêutica, as plantas e os extrativos vegetais foram e continuam sendo de grande relevância, tendo em vista a utilização das substâncias ativas como protótipos para o desenvolvimento de fármacos e como fonte de matérias-primas farmacêuticas, tanto para a obtenção de fármacos (que são as substâncias ativas isoladas), como para a obtenção de adjuvantes (produtos utilizados na formulação de medicamentos) ou, ainda, de medicamentos elaborados exclusivamente à base de extratos vegetais: os medicamentos fitoterápicos (SCHENKEL et al., 2001).

Trabalho publicado inicialmente na Revista NEXUS Ciência e Tecnologia (ISSN 1519-9525), v.1, n.1, p.24-27, 2001. Re-publicação autorizada pelos editores.

Revista Brasileira de Farmacognosia, V. 12, n. 1, p. 35-40, 2002. 
Como produto final de uma série de sugestões apresentadas por diferentes segmentos da sociedade, foi estabelecida uma legislação para a área de fitoterápicos (Portaria 6/SVS de 31/1/1995), que definiu claramente que fitoterápico é um medicamento com componentes ativos exclusivamente de origem vegetal, e que deve apresentar comprovação de eficácia, segurança e qualidade. Também determinou prazos para a realização de estudos de eficácia e toxicidade para os produtos já existentes no mercado, estabelecendo bases para uma maior aceitação desses produtos. Essa legislação exerceu um papel educativo importante e foi reformulada, mantendo suas características essenciais (Resolução RDC n¹7 de 24/2/2000). Também importante, foi o estabelecimento, no Ministério da Saúde e, posteriormente, na Agência Nacional de Vigilância Sanitária -ANVISA, de uma divisão direcionada especificamente para fitoterápicos. Sem um órgão executivo, o processo não seria completo, qualquer que fosse a legislação estabelecida, pois essa por si só não assegura os instrumentos para a melhoria da qualidade dos produtos no mercado.

No segmento industrial, é nítido o ressurgimento do interesse em produtos naturais como fonte de modelos para fármacos (O'NEIL e LEWIS, 1993; KINGSTON, 1996; SHU, 1998, HARVEY, 2000) e como matéria-prima para desenvolvimento de fitoterápicos (SCHENKEL et al., 2001). Nos EUA, ocorreu uma expansão marcante desse mercado. Por exemplo, para produtos contendo kava-kava, entre 1997 e 1998, foi registrada uma expansão de 461\% e para o hipérico, 190\% (BLUMENTHAL et al., 2000). Dados recentes mostram aumentos na venda de valeriana $(+70,5 \%)$ e chá-verde (+39,4\%), entre 1999 e 2000 (BLUMENTHAL, 2001). Além disso, têm sido desenvolvidos estudos de farmacoeconomia com matérias-primas vegetais, mostrando seu impacto na economia de certos países (DE SMET et al., 2000).

Para que possam ser preparadas monografias oficiais sobre plantas medicinais é indispensável estabelecer conhecimentos botânicos, agronômicos, químicos, farmacológicos e toxicológicos e, apenas após esses estudos é possível, por questões éticas e lógicas, pensar em ensaios clínicos. Numa época em que as exigências de segurança, eficácia e qualidade, estabelecidas pelas agências regulamentadoras de medicamentos, se tornaram mais rígidas, a permanência ou entrada no mercado desses produtos estão relacionadas com o desenvolvimento de estudos científicos objetivando a obtenção de matérias-primas controladas, o desenvolvimento de tecnologias apropriadas para a produção de extratos vegetais e, especialmente, a realização de ensaios clínicos.

No Brasil, vinham sendo realizados inúmeros trabalhos com o objetivo de embasar, cientificamente, a utilização de plantas como recurso terapêutico. Na década de 80 , muitos grupos, na sua quase totalidade concentrados em Instituições de Ensino Superior (IES), realizavam projetos de pesquisa nas áreas da botânica, agronomia, química, farmacologia e tecnologia farmacêutica, e seus esforços eram direcionados para a avaliação das potencialidades da nossa flora. O estado brasileiro exerceu uma ação multiplicadora, favorecendo a geração de conhecimentos e a formação de recursos humanos, indispensáveis nas IES, através do Programa de Pesquisa de Plantas Medicinais, iniciado em 1983, e vinculado à antiga Central de Medicamentos (CEME/MS). A interrupção desse programa, em 1995, exerceu um impacto negativo profundo no desenvolvimento dessas áreas. Destaque-se ainda a deficiência em recursos humanos qualificados para algumas áreas especializadas, como a de desenvolvimento tecnológico e a de ensaios clínicos, que vinham sendo apoiadas pelo referido Programa. No entanto, estes estudos estão sendo retomados apesar da inexistência de uma política para o setor, que poderia potencializar esses esforços isolados.

Nosso país possui a maior base universitária das Américas, excluindo os EUA; nossos cientistas publicam em revistas de grande impacto; nosso sistema de pós-graduação é de 
excelente nível e serve de exemplo para vários outros países; há uma inegável capacitação científica em quase todas as áreas relacionadas com o assunto em pauta; muitas patentes que geraram medicamentos, hoje comercializados por empresas multinacionais, tiveram origem em universidades brasileiras; temos a maior biodiversidade do planeta; algumas universidades brasileiras possuem equipamentos analíticos equivalentes aos das grandes universidades estrangeiras. No entanto, os recursos para financiar tais pesquisas não são suficientes em volume e constância, tendo em vista o alto custo do desenvolvimento destes produtos. Esse fato determina que as pesquisas, realizadas nas IES, não sejam competitivas. Será que este último argumento serviria para explicar totalmente porque não se conseguiu ainda desenvolver e colocar no mercado farmacêutico um fitoterápico genuinamente nacional, apesar de todos os argumentos citados anteriormente? É claro que podemos classificar alguns fitoterápicos disponíveis no mercado como nacionais, tais como aqueles à base de maracujá, espinheirasanta, quebra-pedra, marcela e guaraná, entre outros. Contudo, todos eles carecem de alguma(s) da(s) etapa(s) de avaliação necessária(s) para torná-los competitivos no mercado farmacêutico.

Uma reflexão sobre a produção brasileira de medicamentos, a partir de plantas medicinais, pode nos apontar alguns caminhos para esse questionamento. Alguns pontos dessa reflexão já foram discutidos num documento publicado pela Academia Brasileira de Ciências (FERREIRA, 1998), e que contém ainda muitas estatísticas sobre o assunto.

O problema não é somente a falta de recursos, há também uma ausência de política de produção de medicamentos fitoterápicos. Recentemente, isso foi enfatizado por YUNES et al. (2001), que discutem a necessidade de uma política definida, permanente e comprometida com o desenvolvimento da indústria farmacêutica, especialmente a de fitoterápicos.

Tem sido apontada, também, uma certa dificuldade de interação e cooperação entre os diferentes grupos multidisciplinares que trabalham nesta área. Esforços devem ser feitos, em todos os níveis, para minimizar esse impasse. Iniciativas como os Planos Regionais de Pesquisa, apoiados pelo CNPq/MCT e por órgãos estaduais de fomento, talvez venham colaborar para a solução deste problema.

Existe ainda uma falta de tradição das indústrias farmacêuticas brasileiras em investir em Pesquisa e Desenvolvimento - P\&D - e isto é muito forte nas indústrias de fitoterápicos, geralmente, empresas familiares de pequeno ou médio porte. Dentre essas, apenas algumas poucas se destacam pelo profissionalismo e seriedade com que atuam na área, mantendo inclusive acordos de cooperação com Universidades, objetivando garantir a qualidade, eficácia e segurança de seus produtos. A quase totalidade dos fitoterápicos produzidos com plantas nativas está fundamentada apenas no uso popular dessas plantas (não que isto não seja importante!), mas sem comprovação científica de eficácia e segurança de uso, o que não é aceitável (ERNST et al., 1998). Essa situação, se não for revertida, fará inevitavelmente que as indústrias nacionais de fitoterápicos, que não se adaptarem aos novos tempos (na área de medicamentos, sinônimo de competitividade baseada na qualidade de produtos e serviços) enfrentem dificuldades para sobreviver no futuro ou, na melhor das hipóteses, deixem de usufruir do dinamismo que deverá caracterizar o mercado nos próximos anos. A exemplo do que ocorre com a produção de medicamentos sintéticos, o Brasil corre o risco de, apesar de possuir a maior biodiversidade mundial, tornar-se importador de matérias-primas vegetais e reprodutor de formulações fitoterápicas.

A inexistência no Brasil de instrumentos que façam a necessária interação universidade/ empresa, a exemplo do MIT (EUA) ou o BTG (Inglaterra). As universidades brasileiras já demonstraram que têm competência para formar recursos humanos capacitados e gerar 
conhecimentos, mas não têm o dinamismo necessário para transformar os resultados de seus trabalhos em produtos finais de aplicação tecnológica (BRITO CRUZ, 2000). Essa situação está sendo alterada a partir de propostas inovadoras, que buscam efetivar esta tão necessária interação, como por exemplo, os ETT (Escritórios de Transferência de Tecnologia), muito comuns em países da União Européia ou da América do Norte (DEAN, 2000), ou as redes de difusão, como proposto por França (2001).

\section{CONSIDERAÇÕES FINAIS}

É preciso ressaltar que a biodiversidade brasileira não é conhecida com precisão, tal a sua complexidade. O Brasil é o país com a maior diversidade genética vegetal, contando com mais de 55.000 espécies catalogadas de um total estimado entre 350-550.000 (DIAS, 1996, apud GUERRA e NODARI, 2001) e, claramente, o número de pesquisadores dedicado aos estudos de plantas é ainda reduzido (GOTTLIEB e BORIN, 1997). A situação é paradoxal: as plantas medicinais brasileiras são consideradas como altamente promissoras, mas são pouco conhecidas, sob qualquer ponto de vista. O que está acontecendo atualmente é que está se consumindo fitoterápicos desenvolvidos na Europa e América do Norte, e nomes como hipérico, palmeto, ginkgo, equinácea, cratego, tanacetum, etc. estão se tornando familiares e preferidos por profissionais da saúde que apostam na fitoterapia, bem como pela população. Além disso, produtos estão sendo consumidos sem que sua eficácia e segurança tenham sido comprovadas. Basta lembrar os casos do hipérico ou do ginkgo, para os quais os ensaios clínicos foram desenvolvidos com extratos padronizados, de composição definida.

No nosso mercado, a maioria dos produtos é constituída por cápsulas contendo pós de plantas rasuradas, para os quais não existem comprovações de eficácia e segurança e nem mesmo tradição de uso, já que a ingestão nessa forma é tradicional apenas entre os animais. Essa situação é lamentável, ainda mais considerando que as principais indicações desses produtos são depressão e distúrbios vasculares periféricos, respectivamente (BLUMENTHAL et al., 2000).

É, portanto, indispensável continuar o processo de formação de recursos humanos e lutar pelo estabelecimento de programas direcionados para a investigação científica e tecnológica na área, buscando soluções na privilegiada biodiversidade brasileira, através da descoberta e desenvolvimento de novas moléculas com atividade terapêutica, ou no desenvolvimento de fitoterápicos genuinamente nacionais.

Apesar do insuficiente investimento financeiro para o desenvolvimento científico e tecnológico, a comunidade científica brasileira vem envidando esforços na avaliação de nossos recursos naturais, o que é denotado pela grande quantidade de investigações desenvolvidas, muitas delas referenciadas em SIMÕES et al.(2001).

Fica assim evidente que a aproximação da indústria farmacêutica com a academia é hoje mais do que uma necessidade: ela é a base da sua sobrevivência; da geração de novos empregos, incluindo aqueles profissionais que estão sendo formados nas Universidades brasileiras; e da formação de uma nova mentalidade, que estabelece o uso de nossos recursos naturais, propiciando o desenvolvimento socioeconômico, com o indispensável respeito aos ecossistemas e buscando a manutenção das características culturais do país.

\section{REFERÊNCIAS BIBLIOGRÁFICAS}

BLUMENTHAL, M.; GOLDBERG, A.; BRINCKMANN, J. Herbal medicine - Expanded Comission E monographs. Austin: American Botanical Council, 2000. 
BLUMENTHAL, M. Herb sales down 15 percent in mainstream market. Herbalgram, v. 51, p. 69, 2001.

BRITO CRUZ, C.H. de. A Universidade, a empresa e a pesquisa que o país precisa. Política e Organização da Inovação Tecnológica, v.8, p.5-30, 2000.

DE SMET, P.A.G.M.; BONSEL, G.; VAN DER KUY, A.; HEKSTER, Y.A.; PRONK, M.H.; BRORENS, M.J.A.; LOCKFEER, J.H.M.; NUIJTEN, M.J.C. Introduction to the pharmacoeconomics of herbal medicines. Pharmacoeconomics, v.18, n.1, p.1-7, 2000.

DEAN, P. Building relationships between academia and the pharmaceutical industry. Drug Discovery Today 5(9):377-378, 2000.

ERNST, E.; DE SMET, P.A.G.M.; SHAW, D.; MURRAY, V. Traditional remedies and the "test of time". European Journal of Clinical Pharmacology, v. 54, p.99-100, 1998.

FERREIRA, S.H. (org.) Medicamentos a partir de plantas medicinais no Brasil. Rio de Janeiro: Academia Brasileira de Ciências, 1998.

FRANÇA, T.C.V. Redes de Difusão Universidade-Empresa: um estudo exploratório para a UFSC. Florianópolis, 102p. Dissertação (Mestrado) - Programa de Pós-Graduação em Engenharia de Produção, Universidade Federal de Santa Catarina, 2001.

GOTTLIEB, O.R.;BORIN, M.R.M. Natural products research in Brasil. Ciência e Cultura, v. 49, p.315-320, 1997.

GUERRA, M.P.; NODARI, R.O. Biodiversidade: aspectos biológicos, geográficos, legais e éticos. In: Simões, C.M.O.; Schenkel, E.P.; Gosmann, G.; Mello, J.C.P.; Mentz, L.A.; Petrovick, P.R. (org.) Farmacognosia: da planta ao medicamento. 3.ed. Porto Alegre/Florianópolis: Editora da Universidade UFRGS/ Editora da UFSC, Capítulo 1, p.13-26, 2001.

HARVEY, A. Strategies for discovering drugs from previously unexplored natural products. Drug Discovery Today, v.5, n.7, p.294-300, 2000.

KINGSTON, D.G.I. Natural products as pharmaceuticals and sources for lead structures. In: Wermuth, C. (ed.). The Practice of Medicinal Chemistry. San Diego: Academic, p.101-114, 1996.

O'NEIL, M.J.; LEWIS, J. A The renaissance of plant research in the pharmaceutical industry. In: Kinghorn, A.D.; Ballandrin, M.F. (eds.) Human Medicinal Agents from Plants. Washington: American Chemical Society, p. 48-55, 1993.

SCHENKEL, E.P.; SIMÕES, C.M.O.; MENGUE,S.S.; MENTZ, L. A.; IRGANG, B.E.;STEHMANN, J.R. O espaço das plantas medicinais e suas formas derivadas na medicina científica. Caderno de Farmácia, v.1, p.65-72, 1985.

SCHENKEL, E. P.; GOSMANN, G.; PETROVICK, P. R. Produtos de origem vegetal e o desenvolvimento de medicamentos. In: Simões, C. M. O.; Schenkel, E. P.; Gosmann, G.; Mello, J. C. P.; Mentz, L. A.;. Petrovick, P.R. (org.) Farmacognosia: da planta ao medicamento. 3.ed. Porto Alegre/Florianópolis: Editora da Universidade UFRGS / Editora da UFSC, Capítulo 15, p. 301332, 2001.

SHU, Y.-Z. Recent natural products based drug development: A pharmaceutical industry perspective. Journal of Natural Products, v.61, p.1053-1071, 1998.

SIMÕES, C.M.O.; MENTZ, L.A; SCHENKEL, E.P.; IRGANG, B.E.;STEHMANN, J.R. Plantas da medicina popular no Rio Grande do Sul. Porto Alegre: Editora da Universidade UFRGS, 1986. 
SIMÕES, C. M. O.; SCHENKEL, E. P.; GOSMANN, G.; MELLO, J. C. P.; MENTZ, L. A.; PETROVICK, P.R. (org.) Farmacognosia: da planta ao medicamento. 3.ed. Porto Alegre/ Florianópolis: Editora da Universidade UFRGS / Editora da UFSC, 2001.

YUNES, R.A.; PEDROSA, R.C.; CECHINEL FILHO, V. Fármacos e fitoterápicos: a necessidade do desenvolvimento da indústria de fitoterápicos e fitofármacos no Brasil. Química Nova, v.24, n.1: 147-152, 2001.

*Autor para correspondência:

Profa.Dra.Cláudia Maria Oliveira Simões Departamento de Ciências Farmacêuticas Centro de Ciências da Sáude Universidade Federal de Santa Catarina Campus Universitário - Trindade 88040-900 - Florianópolis - SC e-mail: claudias@reitoria.ufsc.br 